\title{
Complexity of health news reporting on breast implant- associated anaplastic large cell lymphoma
}

\author{
Julia A. Cook MD ${ }^{1}$ | Sarah E. Sasor MD² (D) | Sunil S. Tholpady MD, $\mathrm{PhD}^{1}$ | \\ Michael W. Chu MD ${ }^{3}$ | Arash Momeni MD ${ }^{4}$ \\ ${ }^{1}$ Plastic \& Reconstructive Surgery, Indiana University School of Medicine, Indianapolis, Indiana \\ ${ }^{2}$ Section of Plastic Surgery, University of Michigan, Ann Arbor, Michigan \\ ${ }^{3}$ Plastic \& Surgery, Kaiser Permanente, University of Southern California, Los Angeles, California \\ ${ }^{4}$ Plastic \& Reconstructive Surgery, Stanford University Medical Center, Stanford, California \\ Correspondence \\ Sarah E. Sasor, Section of Plastic Surgery, University of Michigan, Ann Arbor, Michigan \\ Email: ssasor@gmail.com
}

Anaplastic large cell lymphoma (ALCL) is a rare, non-Hodgkin's lymphoma characterized by abnormal growth of $\mathrm{T}$ lymphocytes and overexpression of protein cytokine receptor CD30. ALCL can affect multiple parts of the body, including the lymph nodes, skin, and breast. ALCL of the breast is exceedingly rare, affecting approximately 3 per 100 million women per year in the United States. ${ }^{1}$

Public attention to breast implant-associated ALCL (BIA-ALCL) piqued in March 2017 when the U.S. Food and Drug Administration (FDA) released a report of 359 cases and 9 deaths attributed to BIA$\mathrm{ALCL}^{2}$ The New York Times responded with the popular article "Nine Deaths are Linked to Rare Cancer From Breast Implants". ${ }^{3}$

Breast implant placement is one of the most common procedures performed worldwide, with approximately 1.5 million augmentations and 223000 breast reconstructions with implants performed each year. ${ }^{4}$ A disease possibly related to implants, therefore, has potential to generate questions, incite fear, and produce anxiety.

Previous studies demonstrate that $48.6 \%$ of Internet users first turn to the Internet with health care questions ${ }^{5}$; thus, it is imperative that online information be accurate, unbiased, and easy to understand. The American Medical Association (AMA), National Institute of Health (NIH), and U.S. National Library of Medicine recommend that medical information be written at a sixth-grade reading level. ${ }^{6}$ Unfortunately, online resources often far exceed the health care literacy levels of patients. ${ }^{7}$ The purpose of this study was to evaluate the reading complexity of BIA-ALCL information provided by national health care entities and online news outlets.

Patient resource sections of Web sites by the American Society of Plastic Surgeons (ASPS), American Society of Aesthetic Plastic Surgery (ASAPS), and Food and Drug Administration (FDA) were searched for free information regarding BIA-ALCL. The top ten most frequented online news sites in the United States $^{8}$ were searched using the terms "ALCL," "lymphoma," "breast implant," and "implant cancer." Articles from all years discussing the link between $A L C L$ and breast implants were included.

Online resources were formatted into plain text. Multimedia, images, opinion articles, and audio resources were excluded. Readability analyses were performed using the Readability Studio Professional Edition version 2012.1 software (Oleander Software, Ltd, Vandalia, $\mathrm{OH}$ ). Five readability tests were used to evaluate each article: Flesh-Kincaid Grade Level (FKGL), Simple Measure of Gobbledygook (SMOG) Readability Index, Gunning Fog Index (GFI), Automated Readability Index (ARI), and Coleman-Liau Index (CLI) (Figure 1). A $Z$ test was used to analyze the data (SPSS Statistics, Chicago, IL).

Forty-eight articles from 12 sources met inclusion criteria. Dates ranged from November 2008 to March 2017. The ASPS, ASAPS, and FDA were the only national medical entities to offer verified patient information on BIA-ALCL. Eighteen total resources were identified. Nine of the top ten online news Web sites published articles on BIA-ALCL, including CBS News, NBC News, ABC News, Fox News, Time, USA Today, The Washington Post, The New York Times, and Daily Mail. Thirty articles were posted by online news outlets.

A time line of article releases is found in Figure 2. Twenty-five of the thirty (83.3\%) online news articles were published within 1 month of national medical entity article publications. Twenty-three online news articles (76.7\%) cited FDA reports on BIA-ALCL; 17 online news articles (56.7\%) cited press releases from the ASPS or ASAPS.

The overall average reading grade level for all BIA-ALCL online information was 12.7. The combined grade level of FKGL, GFI, CLI, SMOG, and ARI was significantly higher for national medical entity resources (13.7) compared to online news articles $(12.1 ; P<0.01)$. Information provided by national medical entities was written at significantly higher grade levels than online news sources for all readability scales except Flesch-Kincaid Grade Level (Table 1). 

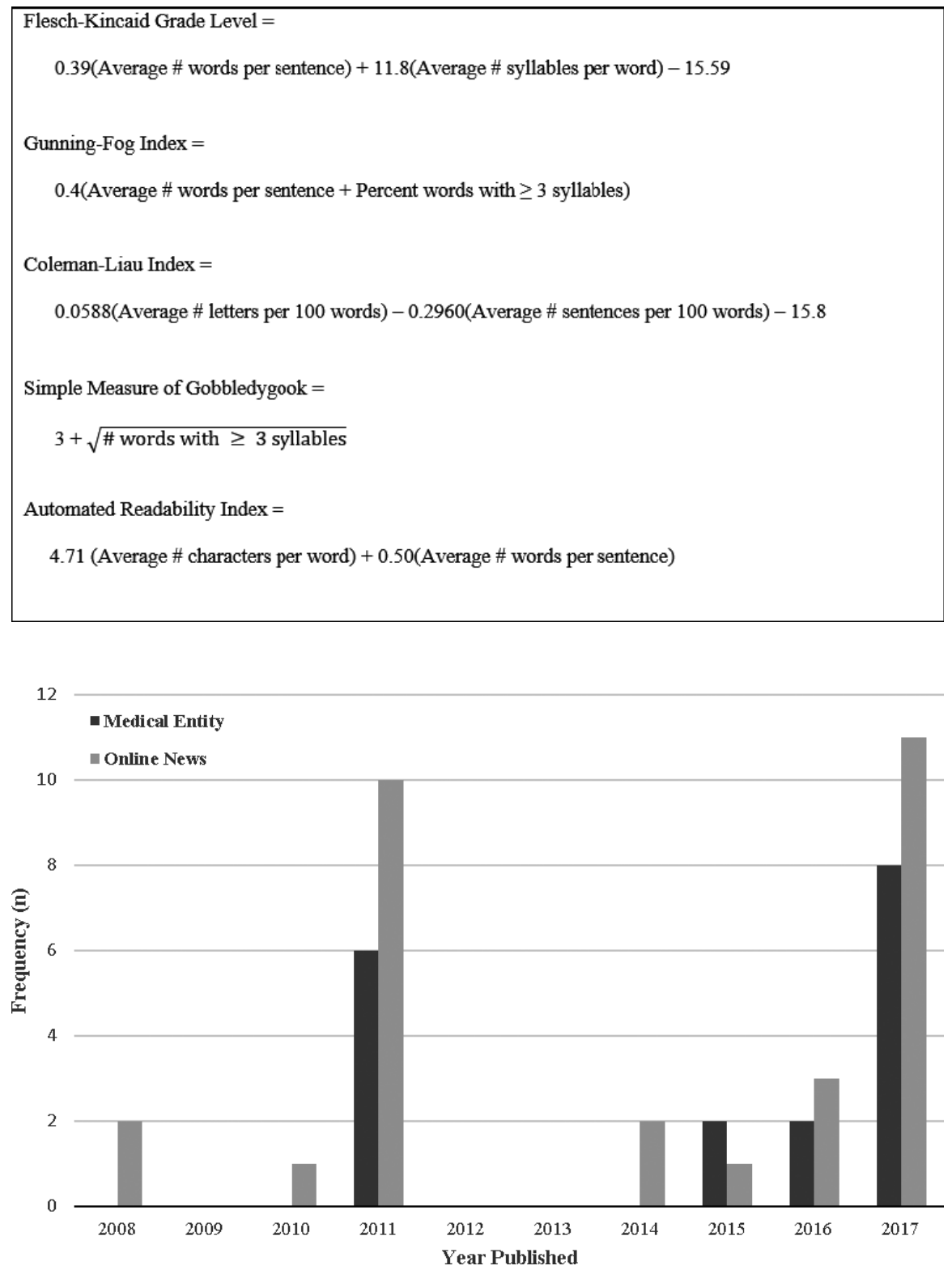

FIGURE 1 Readability scales

FIGURE 2 Temporal frequency of BIAALCL publications
TABLE 1 Reading grade level of BIA-ALCL resources

\begin{tabular}{lllc} 
& $\begin{array}{l}\text { National medical } \\
\text { entities }\end{array}$ & $\begin{array}{l}\text { Online } \\
\text { news }\end{array}$ & $\begin{array}{l}P \text { - } \\
\text { value }\end{array}$ \\
\hline $\begin{array}{l}\text { Flesch-Kincaid Grade } \\
\text { Level }\end{array}$ & $12.7 \pm 2.8$ & $11.5 \pm 1.6$ & 0.10 \\
\hline Gunning Fog Index & $14.6 \pm 3.2$ & $12.9 \pm 1.7$ & 0.04 \\
\hline Coleman-Liau Index & $13.7 \pm 1.7$ & $11.6 \pm 1.1$ & $<0.001$ \\
\hline SMOG Grade & $14.1 \pm 2.2$ & $12.8 \pm 1.3$ & 0.001 \\
\hline $\begin{array}{l}\text { Automated Readability } \\
\text { Index }\end{array}$ & $13.1 \pm 3.8$ & $11.9 \pm 2.0$ & 0.02 \\
\hline
\end{tabular}

Of the national medical entity resources, the ASPS resources had the highest combined grade level (14.6) compared to both the ASAPS (13.1, $P=0.04)$ and the FDA (12.8, $P=0.003)$. Plastic surgery national society (ASPS and ASAPS) resources were written at a higher combined grade level (14.1) compared to FDA resources
(12.8, $P=0.01)$ and online news articles (12.1; $P<0.001)$. There was no significant difference in combined grade level between FDA and online news articles $(P=0.09)$.

Although BIA-ALCL is rare, it is of concern to a large number of patients and health care providers. Individuals concerned about the safety of breast implants turn to the Internet for more information and should find articles written at the sixth-grade reading level. ${ }^{6}$ This study demonstrates that information published by ASPS, ASAPS, and the FDA exceeds the recommended level by seven grade levels; news articles exceed recommendations by six grade levels. This difference may explain why patients prefer online news stories to official health care resources. If educational materials from medical societies were more easily understood, perhaps patients would seek information directly from health care agencies.

Online news publications have closely paralleled medical literature. The majority of online news articles included in this study cited 
information provided by national medical societies and federal agencies. Despite this, it is well-documented that news articles are often incomplete or taken out of context. ${ }^{9}$

While there is no consensus about a method to determine the appropriateness of educational material for patients, readability instruments can quantify the complexity of written text. Several readability scales were used in this analysis, each of which uses a unique algorithm with variables of text complexity. To maximize reader comprehension, authors should write in a clear, concise manner and limit the use of complex words and medical jargon.

Online information on BIA-ALCL on the Web sites of the national plastic surgery societies and the FDA is written at levels that far exceed the recommended reading level of sixth grade. When new diseases emerge, there is often a reaction of fear that must be tempered with information and expert recommendations. The authority on breast implants is the plastic surgery national societies and federal regulatory agencies; mainstream media frequently cite literature published by these national entities. Unfortunately, while news outlets may be more popular and written at a lower complexity, they can be incomplete and lack proper context. Therefore, written medical information needs to be written at a level that all patients understand.

\section{ORCID}

Sarah E. Sasor (iD https://orcid.org/0000-0002-0163-9258

\section{REFERENCES}

1. Altekruse SF, Kosary CL, Krapcho $M$, et al. SEER cancer statistics review 1975-2007. https://seer.cancer.gov/archive/csr/1975_2007. Accessed June 10, 2017.
2. Food and Drug Administration. Breast implant-associated anaplastic large cell lymphoma (BIA-ALCL). https://www.fda.gov/MedicalDevice s/ProductsandMedicalProcedures/ImplantsandProsthetics/BreastImpla nts/ucm239995.htm. Accessed June 10, 2017.

3. Grady D. Nine deaths are linked to rare cancer from breast implants. New York Times. March 21, 2017. https://www.nytimes.com/2017/03/ 21/health/breast-implants-cancer-deaths.html?_r=1. Accessed June 10, 2017.

4. International Society of Aesthetic Plastic Surgery. Global survey released by ISAPS reports increase over one million cosmetic and aesthetic procedures performed in 2015. https://www.isaps.org/Media/ Default/global-statistics/Global\%20Survey\%20Press\%20Release_V2. pdf. Accessed June 10, 2017.

5. Hesse BW, Nelson DE, Kreps GL, et al. Trust and sources of health information: the impact of the Internet and its implications for health care providers: findings from the first Health Information National Trends Survey. Arch Intern Med. 2005;165:2618-2624.

6. United States National Library of Medicine. How to write easy-toread health materials. https://medlineplus.gov/etr.html. Accessed June 10, 2017.

7. Cook JA, Sasor SE, Tholpady SS, Momeni A, Chu MW. Hand surgery resources exceed American health literacy. Hand (NY). 2017;13:547551. https://doi.org/10.1177/1558944717725384

8. Comscore. Revised top 50 digital media properties for October and November 2016. http://www.comscore.com/Insights/Rankings/Re vised-Top-50-Digital-Media-Properties-for-October-and-November2016. Accessed June 10, 2017.

9. Niederdeppe J, Frosch DL, Hornik RC. Cancer news coverage and information seeking. J Health Commun. 2008;13:181-199.

How to cite this article: Cook JA, Sasor SE, Tholpady SS, Chu MW, Momeni A. Complexity of health news reporting on breast implant-associated anaplastic large cell lymphoma.

Breast J. 2019;25:163-165. https://doi.org/10.1111/ tbj.13189 